\title{
GPR 3D aplicado no Sítio Controlado de Geofísica Forense da UFPR
}

Rafael Espindola Canata, LPGA-UFPR; Francisco José Fonseca Ferreira, LPGA-UFPR; Welitom Rodrigues Borges, IG-UnB; Fábio Augusto da Silva Salvador, INC-DPF; Alessandra de Barros e Silva Bongiolo, LPGA-UFPR.

Copyright 2019, SBGf - Sociedade Brasileira de Geofísica

This paper was prepared for presentation during the $16^{\text {th }}$ International Congress of the Brazilian Geophysical Society held in Rio de Janeiro, Brazil, 19-22 August 2019.

Contents of this paper were reviewed by the Technical Committee of the $16^{\text {th }}$ International Congress of the Brazilian Geophysical Society and do not necessarily represent any position of the SBGf, its officers or members. Electronic reproduction or storage of any part of this paper for commercial purposes without the written consent of the Brazilian Geophysical Society is prohibited.

\section{Abstract}

In 2016, the Laboratory for Research Applied Geophysics (LPGA) in partnership with the Federal Police of Paraná State and the University of Brasilia built a Controlled Site of Forensic Geophysics for the improvement of forensic science. Several objects of paleontology, archeology and forensics were buried in a clay soil, typical of the region. This study shows the results of 2D and 3D Ground Penetration Radar (GPR) using the $400 \mathrm{MHz}$ antenna running on the controlled site. The high content of clay present in the soil, below 0.5 meters deep, greatly attenuated the GPR signal. Thus, only the targets with high electrical impedance were imaged in the sections of GPR.

\section{Introducão}

No Brasil, após a expedição pela busca dos vestígios de pessoas desaparecidas na Guerrilha do Araguaia (BORGES et al., 2010), ocorreu um interesse dos geocientistas pelo desenvolvimento e aprimoramento da geofísica forense nas Universidades. Como a pesquisa em geofísica forense envolve a busca por objetos ocultos relacionados a crimes, a capacitação técnica dos geocientistas precisa de nomeação jurídica. Assim para capacitar as equipes técnicas criam-se áreas controladas, como exemplo tem-se: o Campo de Teste Controlados de Geofísica Forense, Ambiental e de Resgate (FORAMB) em Belém no Pará; o Sítio Controlado de Criminalística (SITICRIM) no Instituto Nacional de Criminalística da Polícia Federal de Brasília; e o Sítio Controlado de Geofísica Forense (SCGF) na Fazenda Água Limpa da Universidade de Brasília, no Distrito Federal. No Brasil existem diversas pesquisas com o objetivo de verificar a aplicabilidade dos métodos geofísicos em alvos forenses, ambientais e arqueológicos (NASCIMENTO, 2009; ALVES et al., 2013; BUSO et al., 2016 e CAVALCANTI, 2017).

Em 2016, como forma de estabelecer a geofísica forense na Universidade Federal do Paraná (UFPR), instalou-se o primeiro Sítio Controlado de Geofísica Forense da Universidade Federal do Paraná (SCGF-UFPR), localizado no Campus Centro Politécnico - Jardim das Américas, na cidade de Curitiba, Estado do Paraná. (Fig. 1).
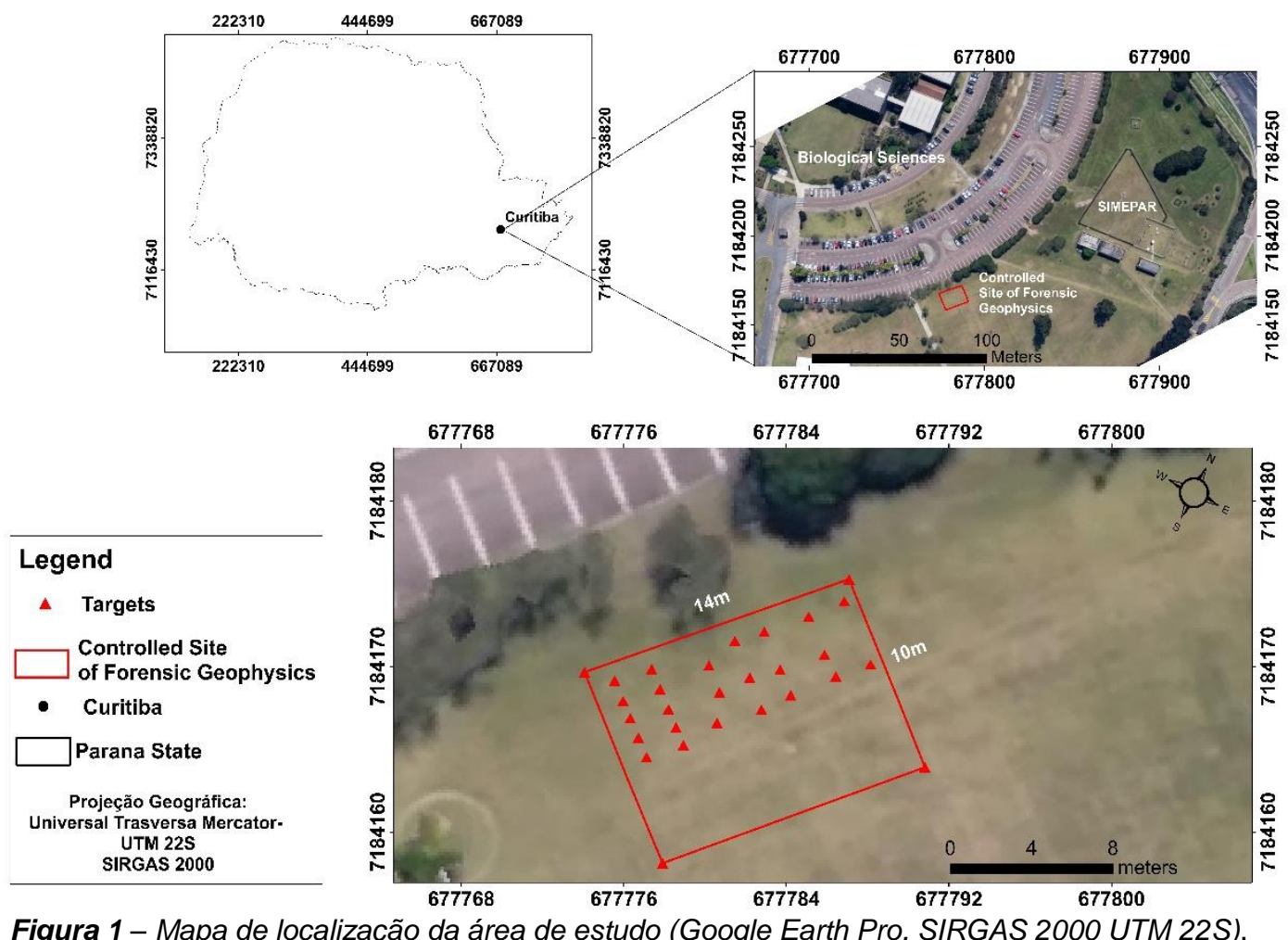
O SCGF possibilitará o aprimoramento e a formação de profissionais em geofísica forense. A área do sítio controlado corresponde a $14 \mathrm{~m} \times 10 \mathrm{~m}\left(140 \mathrm{~m}^{2}\right)$ em um contexto geológico associado principalmente a sedimentos argilosos provenientes da Formação Guabirotuba (Quaternário). Neste local enterraram-se materiais que simulem situação de arqueologia (pedras, cerâmicas e tijolos), forense (ossos bovino, calçados, calças, tambores plásticos vazios e com armas destruídas) e paleontologia (madeira petrificada de pequenas dimensões), os quais foram instalados em profundidades rasas (entre 0,12m a 0,45m; Figura 2).

Neste trabalho mostram-se alguns resultados do imageamento 2D e 3D dos artefatos instalados no FGCSS, obtidos com o método do radar de penetração de solo (GPR) usando-se antenas blindadas de $400 \mathrm{MHz}$, em um solo argiloso saturado com água em decorrência de chuvas.

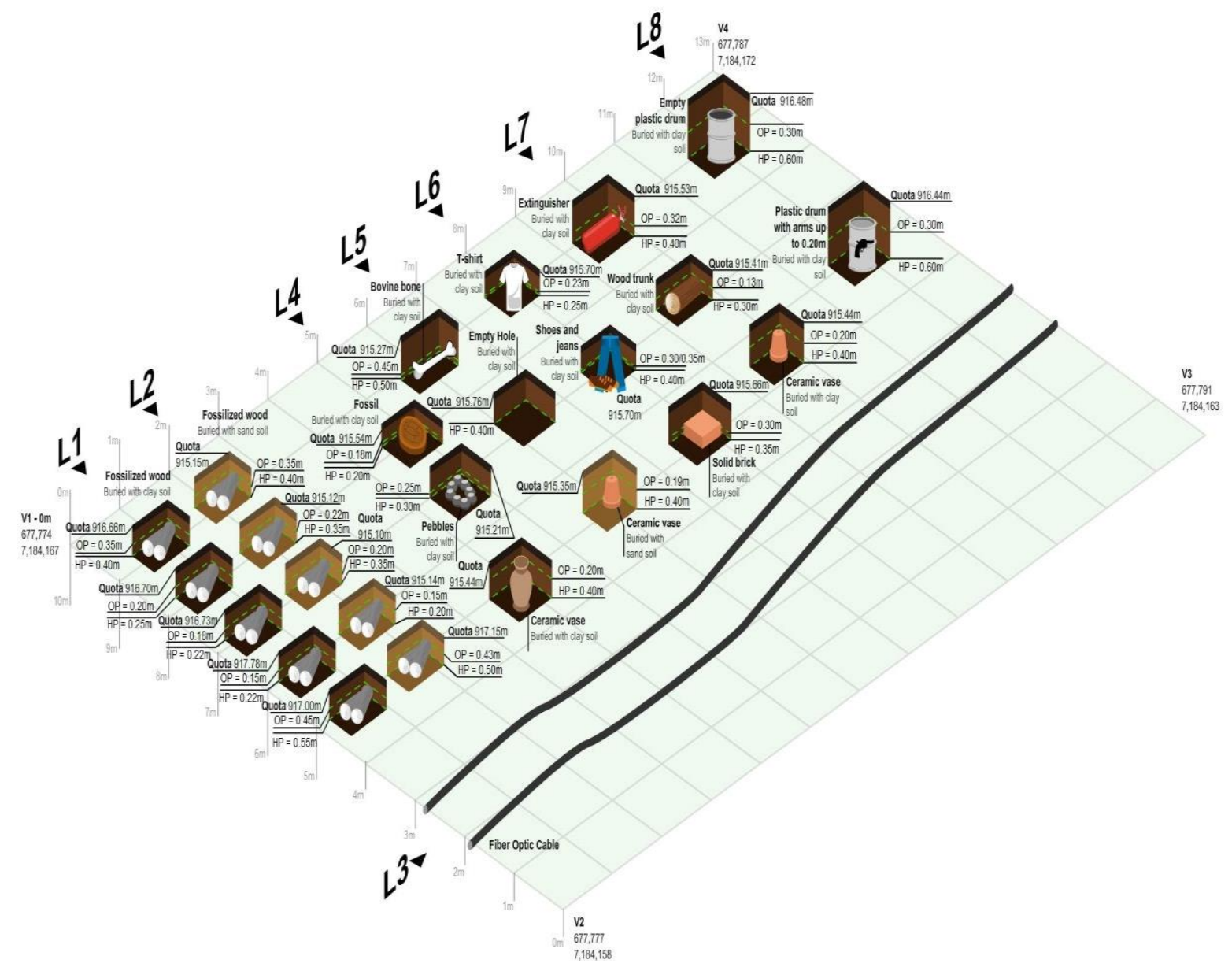

Figura 2 - Croqui do Sítio Controlado de Geofísica Forense da UFPR com a localização, profundidade do topo (OP) e base $(H P)$, e tipo de material instados na área.

\section{Método e Aquisição}

Entre os vários métodos geofísicos aplicados para a forense e arqueologia, destaca-se o GPR pela sua versatilidade, agilidade em campo e dinâmica em tempo real do resultado. O funcionamento do GPR consiste na irradiação contínua de ondas eletromagnéticas por meio de uma antena transmissora; as ondas que se propagam no meio refletem-se ou difratam-se em consequência de diferenças de impedância elétrica (ANNAN, 2001). Deste modo, as ondas eletromagnéticas refletidas são captadas em uma antena receptora, armazenadas e visualizadas em uma unidade de controle.
$\mathrm{Na}$ aquisição geofísica utilizou-se um Sistema de GPR SIR3000 (GSSI) com antena blindada de $400 \mathrm{MHz}$. Os registros de traços foram obtidos no modo constant offset com perfis espaçados de $0,10 \mathrm{~m}$, para a construção de volumes 3D, num total de 140 perfis. Os dados foram registrados continuamente, com os seguintes parâmetros de aquisição: espaçamento entre traços de 0,02 metro, 512 amostras por traço e janela temporal de $50 \mathrm{~ns}$. E como forma de auxiliar o georreferenciamento dos dados 3D, fixou-se na superfície um cabo de aço de 1/4 de polegada (Fig. 3) para causar uma reflexão em um ponto conhecido. 
O processamento de dados GPR ocorreu no software ReflexW, versão 7.0 (Sandmeier 2010). A rotina de processamento para seções $2 D$ e $3 D$ consistiu em: correção do tempo zero (define o primeiro registro do sinal GPR para tempo zero no solo); corte de tempo 30ns (limita o registro de tempo GPR, maximizando o tempo de processamento); remoção do ganho de campo (remove a curva de ganho e obtém dados brutos sem amplificação temporal), ganho (aumenta a amplitude do sinal perdida em decorrência da atenuação da onda durante sua propagação); filtro 2D (elimina eventos coerentes como refletores horizontais); filtro 1D (remove ruídos incoerentes); Migração 3D (fk migração-stolt) e conversão de tempo / profundidade (converte os eventos de reflexão em uma posição real em termos de profundidade abaixo do nível do solo).

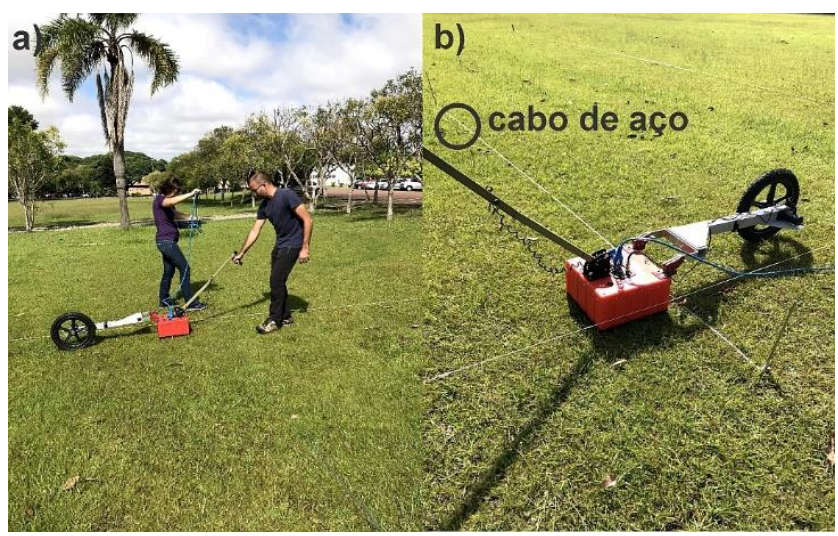

Figura 3 - a) Foto ilustra a aquisição de campo e b) Foto evidencia o cabo de aço utilizado como guia para georreferenciamento dos dados $3 D$.

\section{Resultados}

Primeiramente analisaram-se os radargramas 2D, e posteriormente os cortes em profundidade dos blocos 3D. Com as análises das seções 2D e o conhecimento das profundidades dos alvos obteve-se a variação das velocidades da onda eletromagnética dos alvos instalados. Os resultados da análise de velocidade evidenciaram um intervalo de velocidade entre $0,054 \mathrm{~m} / \mathrm{ns}$ a $0,077 \mathrm{~m} / \mathrm{ns}$, e o tempo de identificação das hipérboles de difração (artefatos) de $8,50 \mathrm{~ns}$ a $13 \mathrm{~ns}$. Com as velocidades obtidas evidenciam-se refletores até a profundidade máxima de 0,8m (Fig. 4a e 4b), após esta profundidade todo o sinal é absorvido pela argila úmida.

As figuras 5 e 6 ilustram seções de GPR 2D e as algumas das anomalias relacionadas aos artefatos imageados. As figuras $5 a$ e $5 b$ exibem as seções $2 \mathrm{D}$ adquiridas sob as madeiras petrificadas que foram recobertos por solo argiloso (do local) e por areia fina, respectivamente. Comparando-se as respostas entre as duas seções $2 \mathrm{D}$, o melhor imageamento está relacionado a seção que contém as madeiras petrificadas enterradas na areia fina (Fig. 5b), nesta figura os refletores de alta amplitude na profundidade de $0,10 \mathrm{~m}$ estão associados as cavas realizadas para instalação dos alvos e ao contraste da interface matéria orgânica com o inicio da areia fina.

Nas figuras $6 a, 6 b$ e $6 c$ estão ilustradas algumas das anomalias 2D referentes a determinados alvos como: seixos, vaso de cerâmica enterrado na areia fina e tambor de plástico preenchido com armas, respectivamente. A diferença de um padrão anômalo hiperbólico observado nestas figuras estão relacionados a alguns fatores: ao tamanho do objeto investigado, a sua geometria, a forma com que este alvo foi instalado em subsuperfície, as propriedades composição físico-químicas dos objetos e do meio investigado. A presença de água no local e o baixo contraste dielétrico dificultou 0 imageamento de determinados alvos como: tênis/calça jeans, osso bovino, camiseta e tijolos, dentre outros.

Após a análise 2D, iniciou-se o ajuste do posicionamento dos traços (a partir da reflexão hiperbólica do cabo de aço) para uma melhor visualização do bloco 3D. Posteriormente, diversos depth slice foram executados para estimar a profundidade dos alvos investigados, o seu posicionamento e a forma geométrica dos objetos.

O depth slice $(0,03 \mathrm{~m})$ ilustra nas posições (X- distância: 4m / Y- distância: 0-4m) uma anomalia com uma amplitude de sinal (média a alta) que reflete o cabo de aço utilizado para auxiliar na aquisição, bem como a presença de refletores associados as cavas utilizadas para implantação dos alvos (Fig. 7a).

As figuras $7 \mathrm{~b}$ e 7c correspondem ao depth slice na posição de $0,35 \mathrm{~m}$, asanomalias de alta reflectância (círculos vermelhos) estão relacionadas as madeiras petrificadas ( $F 1$ e F5, vide figura $5 b$ ) enterradas em um meio arenoso. E nas posições (X- distância: $2 \mathrm{~m}$ a $3 \mathrm{~m}$ ) e (Y-distância: $0 \mathrm{~m}$ a $3 \mathrm{~m}$ ) observa-se uma zona de alta reflectância inclinada que corresponde à escavação realizada para implantação dos cabos de fibra óptica.

As figuras $8 \mathrm{a}, 8 \mathrm{~b}$ e $8 \mathrm{c}$ ilustram um corte do bloco 3D referente a área do sitio controlado que contem os tambores de plástico preenchido com arma e vazio. A figura 8a, dado não migrado, mostra uma dispersão maior das anomalias e também a presença de ruídos aleatórios próximos aos alvos imageados, o que dificulta a visualização/identificação destes alvos. Na figura 8b, dado migrado, observa-se uma pequena diminuição dos ruídos, entretanto não houve uma diferença no delineamento dos alvos. Deste modo, optou-se em realizar uma interpolação $3 \mathrm{D}$, vista na figura $8 \mathrm{c}$, a qual resultou em uma melhora na visualização/delineamento das anomalias tornando-as mais concêntricas (se aproximando a forma do objeto investigado) e uma diminuição considerada dos ruídos aleatórios próximos aos alvos detectados. 

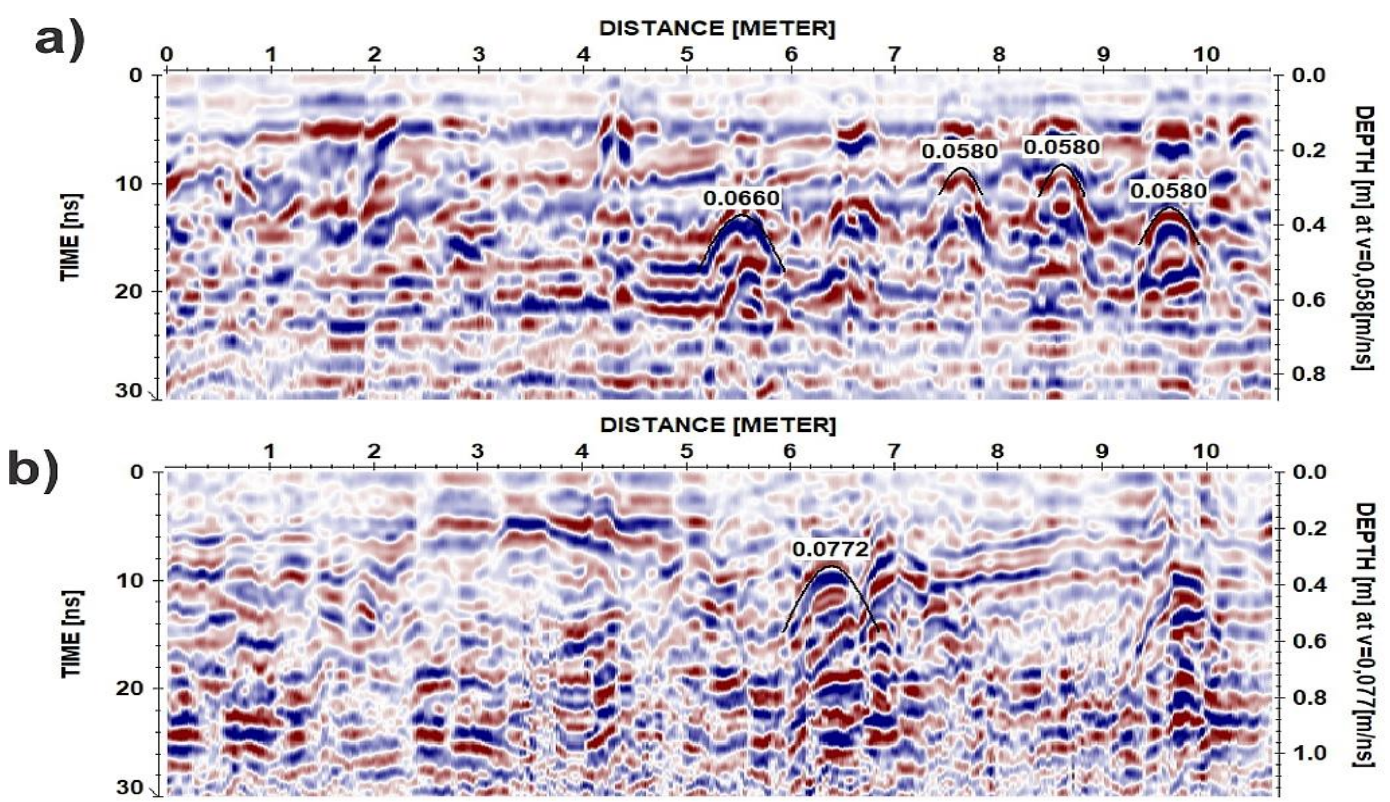

Figura 4 - Seções $2 D$ com as hipérboles de ajuste de velocidade sobrepostas: a) Seção adquirida sob as madeiras petrificadas e b) Seção adquirida sob os tambores de plásticos.

\section{Conclusões}

Na presente pesquisa, os resultados obtidos com o GPR através da antena de $400 \mathrm{MHz}$ foram satisfatórios, identificando vários alvos instalados no sítio controlado, especialmente aqueles que apresentam um maior coeficiente de reflexão. Em contrapartida, a saturação do meio contribuiu para uma maior atenuação do sinal da onda eletromagnética dificultando a detecção dos alvos que possuem um baixo contraste de reflexão.

A utilização de um cabo de aço como guia para as aquisições foi bem-sucedida substituindo a ausência da instalação de um cano guia em subsuperfície. As interpolações aplicadas no modo 3D resultaram em um melhor imageamento dos alvos detectados e por vezes uma eliminação de ruídos. Por fim, pretende-se realizar aquisições com a antena de $900 \mathrm{MHz}$ para imagear os alvos não detectados.

\section{Agradecimentos}

Os autores gostariam de agradecer à Polícia Federal do Brasil (Superintendência Regional do Paraná) Universidade Federal do Paraná, Universidade de Brasília e a Universidade Estadual de Santa Catarina, pela colaboração na pesquisa. A Fundação Capes - Ministério da Educação pelo apoio na pesquisa através do financiamento de bolsa para o doutorando Rafael Espindola Canata. E o Prof. Francisco José Fonseca Ferreira foi apoiado nesta pesquisa por bolsas do CNPq (contrato 06978 / 2015-6).

\section{Referências}

ANNAN, A. P. Ground penetrating radar workshop notes. Sensors; Software, Inc. Internal Report, p.130. 2001
ALVES, L. K.; BORGES, W. R.; BLUM, M. L. B. Mapeamento de alvos forenses com GPR 3D. In: International Congress of the Brazilian Geophysical Society, 13., 2013, Rio de Janeiro. Anais... Rio de Janeiro, 2013, 1 Cd-rom

BORGES, W. R.; BLUM, M. L. B.; BRANCO, R. M. G. C.; SILVA, L. M. C.; PORSANI, M. J.; BRICHTA, A.; AMORIM, A. N.; PEDROSA JUNIOR, N.; SANTOS, V. R. N; BRAGA, L. R. C; ALBUQUERQUE SOBRINHO, J; PÉRICLES DE MACEDO, P. B.; SANTOS, E. C.; SOUZA, J. C. F.; BRASIL, D. L.; MACHADO, M. A.; MARTINS, J. A.; MELLO, G. A. Aplicação de geofísica forense na busca de vestígios de pessoas desaparecidas na Guerrilha do Araguaia. In: IV Simpósio Brasileiro de Geofísica, 2010, Belém. Anais... Belém, 2010, 1 Cd-rom.

BUSO, A. S. O.; BLUM, M. L. B.; BORGES, W. R. Imageamento GPR 3D de alvos forenses na área sítio controlado de criminalística (SITICRIM). In: VII Simpósio Brasileiro de Geofísica, 2016, Ouro Preto. Anais... Ouro Preto, 2016, Cd-rom.

CAVALCANTI, M. Estudos da resposta geofísica em diferentes cenários de sepultamentos. 197 f. Tese (Doutorado de Geofísica) - Instituto de Geociências, Universidade de Brasília, Brasília, 2017.

NASCIMENTO, W. G. Investigação geofísica ambiental e forense nos cemitérios do Bengui e do Tapanã (Belém, Pa). 153 p. Dissertação (Mestrado em Geofisica) Instituto de Geociências, Universidade Federal do Pará, Belém, 2009.

SANDMEIER, K. J. REFLEXW Version 7.4, Windows 9x/2000/NT. Manual do Software, Karlsruhe, Germany, 209p. 2010. 

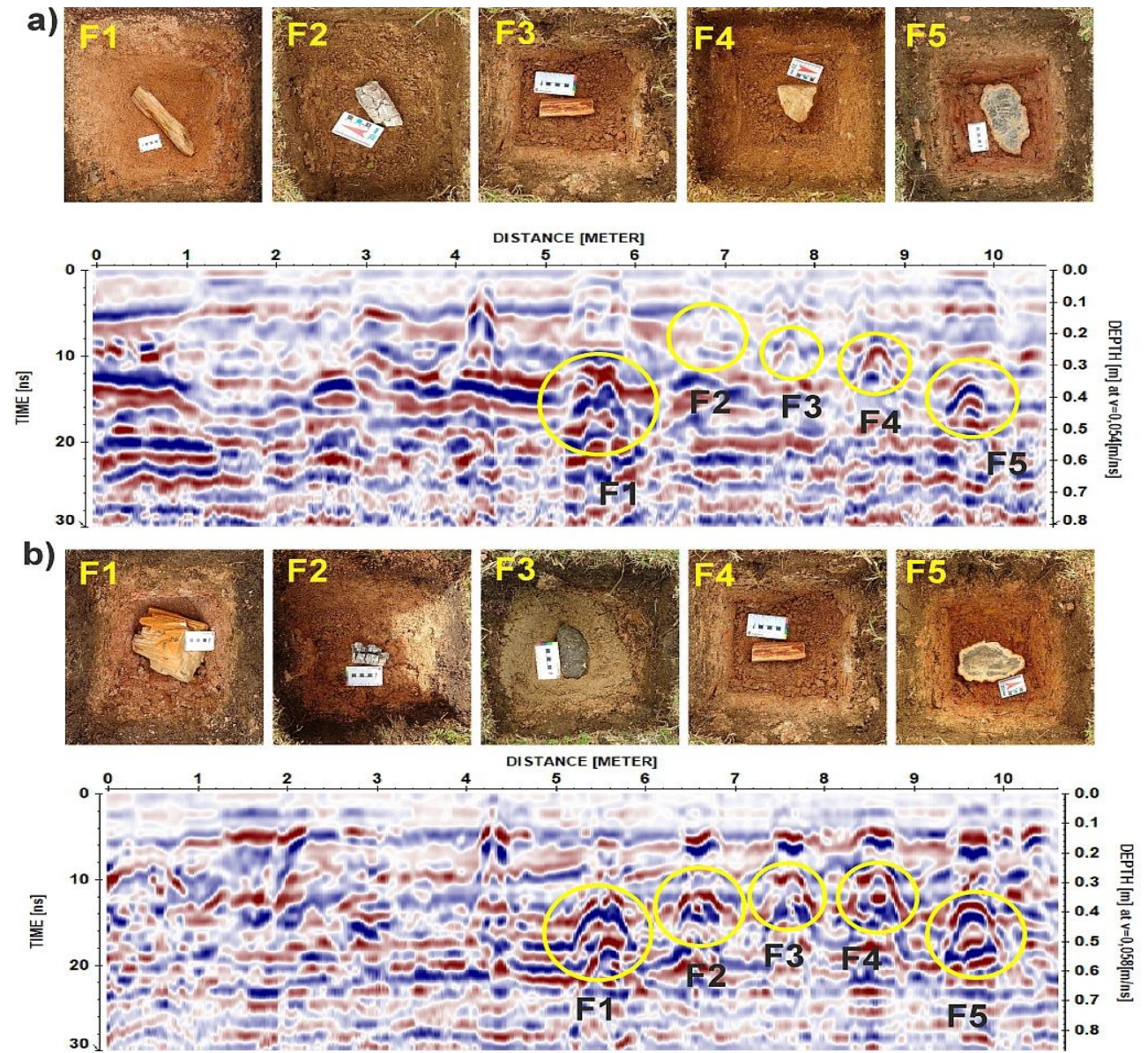

Figura 5 - Seções de GPR e respectivas fotografias dos alvos instalados em cada cava. a) Radargrama adquirido sob as madeiras petrificadas enterradas em solo argiloso e b) Radargrama adquirido sob as madeiras petrificadas enterradas em areia fina.
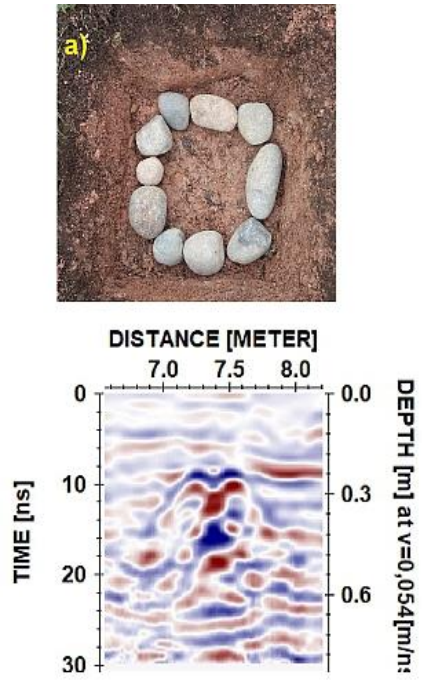
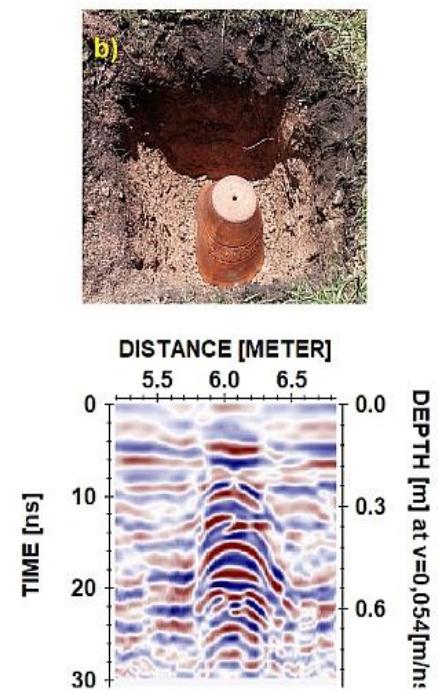
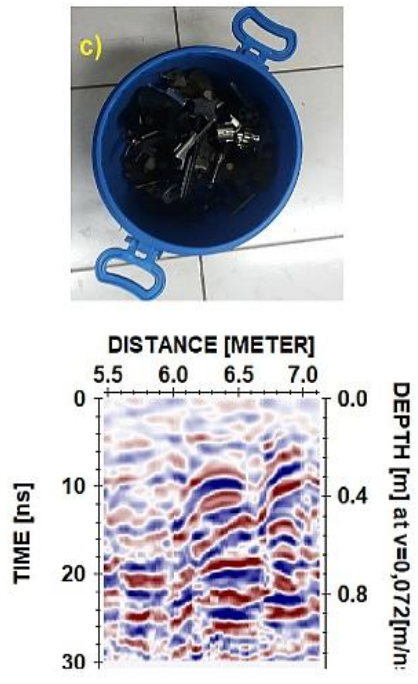

Figura 6 - Fotografias e respectiva anomalia de GPR: a) foto dos seixos (superior) e anomalia hiperbólica (inferior), b) foto do vaso de cerâmica enterrado em areia fina (superior) e anomalia hiperbólica (inferior) e c) foto tambor preenchido com armas danificadas e anomalia hiperbólica. 

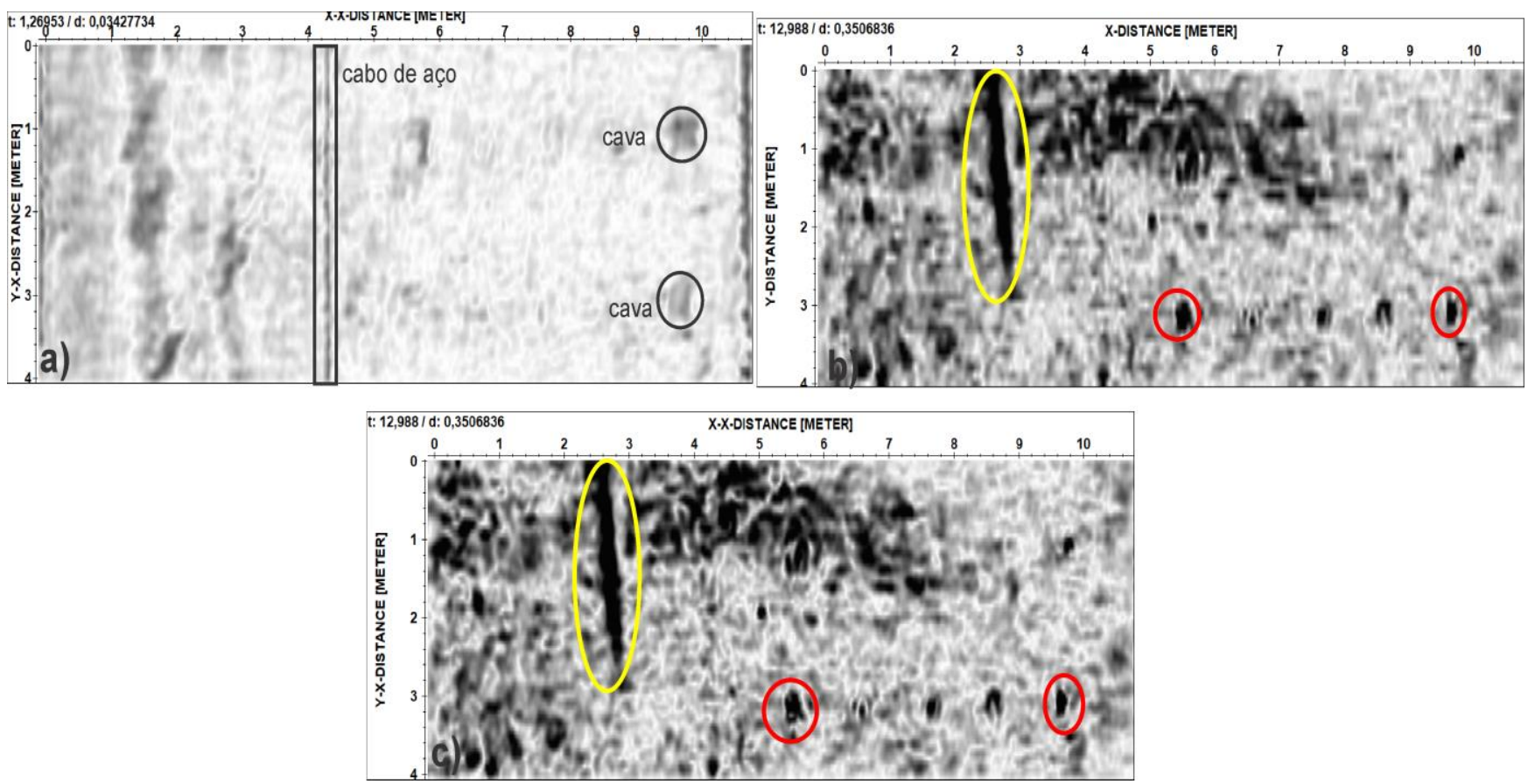

Figura 7 - Cortes em profundidade dos blocos de GPR 3D da área que simulam madeiras petrificadas: a) Corte em profundidade com a anomalia linear relacionado ao cabo de aço guia e as cavas para instalação de dois alvos; b) Dado não migrado; e c) Dado migrado e interpolado. Nas figuras os assinalados em preto representam o cabo de aço e as cavas, em vermelho os fósseis detectados e em amarelo a escavação realizada para implantação do cabo de fibra ótica.
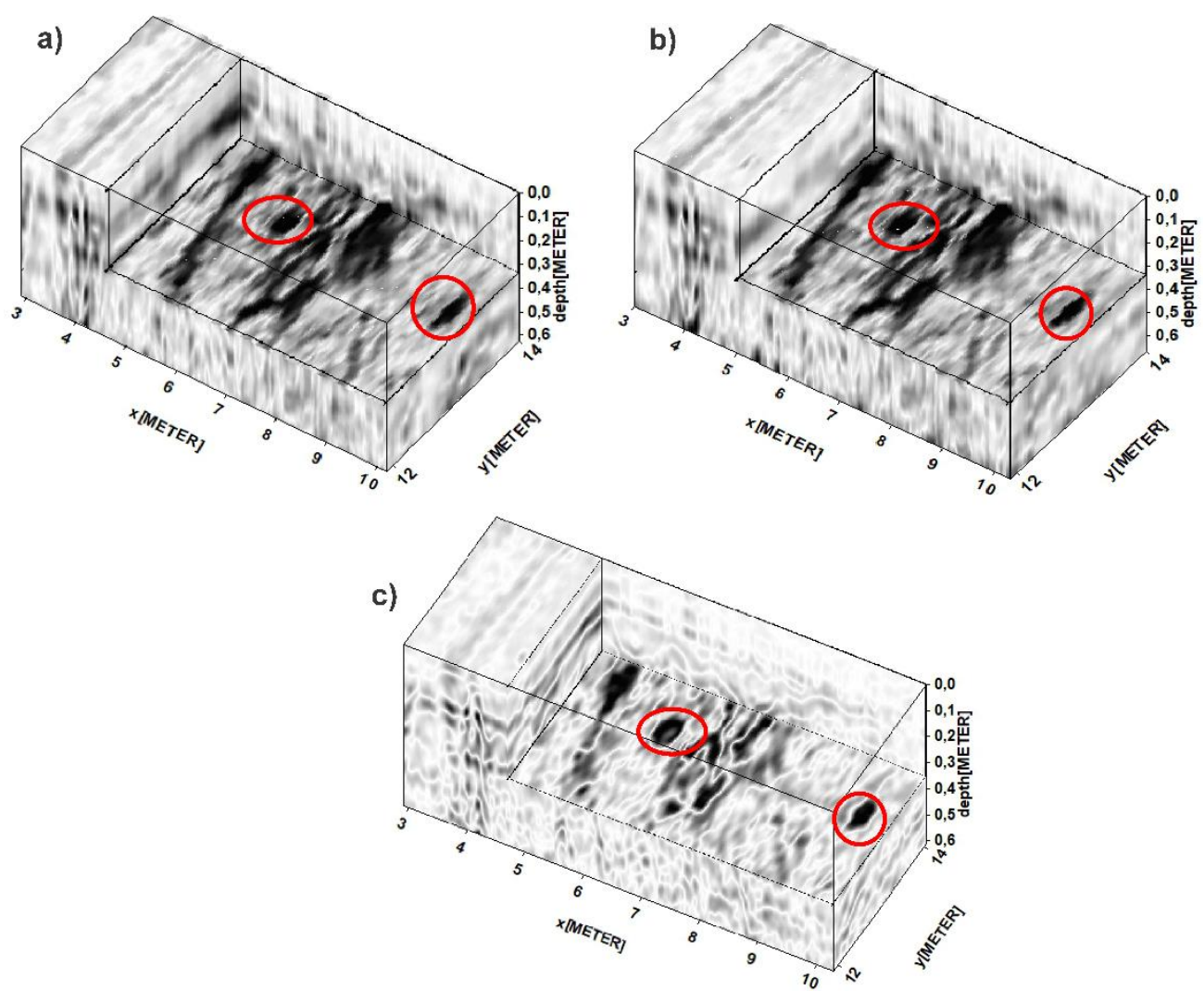

Figura 8 - Blocos de GPR 3D referente à área dos tambores de plástico: a) dado não migrado, b) dado migrado e c) dado interpolado em $3 D$. 